\title{
On Enterprise Architecture Patterns: A Systematic Literature Review
}

\author{
Roberto Rafael García-Escallón ${ }^{1}$ and Adina Aldea ${ }^{2}$ \\ ${ }^{1}$ Master Business Information Technology, University of Twente, Enschede, The Netherlands \\ ${ }^{2}$ Industrial Engineering and Business Information Systems, University of Twente, Enschede, The Netherlands
}

Keywords: Enterprise Architecture Patterns, Enterprise Architecture.

Abstract: $\quad$ Organizations around the world today face many challenges, and not all of them are unique. Such repeatable problems can themselves be solved by reusable solutions. This study focuses on Enterprise Architecture Patterns, reusable solutions to repeating challenges organizations face. Through a systematic literature review, we aim to gather an exhaustive recollection of all such patterns in literature. In order to be as comprehensive as possible, the sample included related fields also researching patterns. The result is a collection of 593 patterns and their respective analysis, which will help practitioners tackle their challenges.

\section{INTRODUCTION}

Enterprise Architecture (EA) is a relatively new field of research that aims to align the objectives of the different areas of an organization (Lankhorst, 2017). Practitioners of this field have many frameworks and methods at their disposal, such as the Zachman framework and The Open Group Architecture Framework (TOGAF), among others (Zachman, 1987; The Open Group, 2018). Most of these methodologies and frameworks describe ways of representing the organization in order to analyze how it is working at the moment and how it should be working in the future (Lankhorst et al., 2009). Organizations are very different from one another but have similarities in their inner workings. Similarities that could also be called patterns.

The definition of patterns comes from Christian Alexander, the author of the book "A Pattern Language" (Alexander et al., 1977). It is used as the base definition for patterns in multiple fields, it builds upon four key attributes. First, patterns are a solution to a recurring problem. Second, the pattern is the core of the solution, meaning the solution has a scope, and does not aim to describe anything that is not needed to solve the problem. Third, the pattern should be usable as many times as needed. And fourth, each specific use of the pattern might look different than the last.

Patterns in the case of Alexander et al. (1977) refer to patterns in architecture, but the concept has been applied to other fields as well. One of the fields using patterns is Computer Science, where they are used as a standardized solution that can be reused in multiple cases, an approach that has become a best practice to solving problems in the field (Gamma and al, 1995). An example is the Facade pattern that defines a central interface of access acting as a front to a complex structure, simplifying the access (Gamma and al, 1995).

Applying patterns to EA would entail that practitioners document both recurring problems and the solutions they use to solve them within their organizations. This documentation would help future organizations explore alternative configurations to their current way of operation, as well as inspire what direction to move to in their future. This approach is mentioned as best practice in the TOGAF, so it is not a new idea, however the execution of the practice is left to the readers (The Open Group, 2018). By having similarities in their functioning, organizations could reuse solutions to the challenges they face often. However, today using publicly available patterns for EA is not a widespread practice. Stemming first from a lack of said public patterns. Thus a first step towards popularizing pattern use is to identify them and their sources.

The goal of this study is to answer the research question "What is the state of the literature of Enterprise Architecture Patterns?" by performing a Systematic Literature Review (SLR), leveraging multiple databases. Furthermore, this study gathers EA patterns and identifies fields related to EA that can serve as sources patterns. In order to gather a holis- 
tic view, and as complete a list of patterns as possible, the query was executed over the full text of the articles, instead of the more popular Title-AbstractKeywords. This scope was set aiming for discovering what other fields related to EA are researching patterns. Such fields were later found to be: Business Model Innovation (BMI), Business Process Management (BPM), and Information Technology Service Management (ITSM).

The contribution to the field is an exhaustive review of EA patterns found in the literature, as well as identifying more fields of research that serve as sources of such patterns. Also, it paves the way for a centralized repository of patterns from multiple fields of research, to be used and applied by Enterprise Architects in the field. Such a set of patterns could be used to enhance current EA tools. Imagine an architect using an EA modelling tool, while defining a new Business Process they could choose how applications support it based on the patterns by Šaša and Krisper (2011) (P12 in the sample). The same way patterns in Computer Science helped tool vendors to offer assistants to expedite the tasks, e.g. automatically applying patterns like the Factory Method as software developers are working (Gamma and al, 1995).

The rest of the article is organized as follows: in section 2 the methodology used is presented, then in section 3 the results of the SLR are shown, then in section 4 the findings are discussed, and finally in section 5 the conclusions are drawn.

\section{METHODOLOGY}

In order to achieve the study's goal the SLR methodology of Rouhani et al. (2015) is used, as it is a very thorough work in the EA field. The method they used is first introduced by Kitchenham and Charters (2007) a guideline for Software Engineering, but was modified for its' use in EA. This method outlines three stages to a SLR: a planning phase, an execution phase and a result analysis phase. In order to enhance this method, some techniques described by Wolfswinkel et al. (2013) will be included, specifically, the backwards and forwards citation steps of their selection phase to detect any work that builds upon patterns that was not present as results of the query, to include additional articles that might be relevant but were not present in the results of the query. In order to execute this last step, Google Scholar was used, which shows both, backward and forward citations, easily. The process is shown in Figure 1.

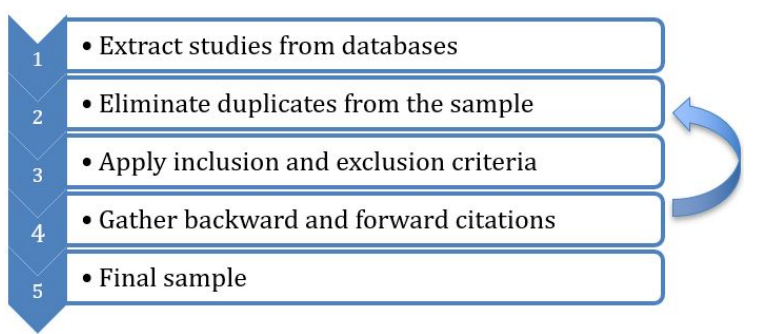

Figure 1: Overall Process of the SLR.

\subsection{Design Phase}

In this phase the design process followed to perform the SLR according to the chosen methodology is presented.

\subsubsection{Research Question}

Identifying patterns, and then apply them to subsequent work is a generalized human practice, this research aims to identify what patterns there have been researched in the EA field. The expectation was to find a list of patterns that could be used to answer some of the challenges today's organizations face. As such, the main Research Question (RQ) to answer follows below. In order to best answer it subsequent four Sub-questions (SQ) were defined.

RQ: What is the state of the literature of EA Patterns?

SQ1: What patterns are present in the sample?

SQ2: What other fields of research are present in the sample?

SQ3: What ways of representing patterns are used?

SQ4: What methodologies are used for pattern extraction?

By identifying other fields that are related to EA in their text the list of patterns will be expanded beyond the ones found strictly in the EA field. This would serve to classify the patterns found based on which field it comes from. The expectation is to find fields that are related to EA, in a way that the patterns found can be used by EA practitioners in the future.

In order to compare the patterns found information regarding how these patterns are represented is gathered. The expectation is to find studies using standard modeling languages like Archimate, UML, BPMN; as well as strictly written descriptions, among others.

In order to compare the studies themselves the methods used to extract the patterns will be gathered. In other words, how did the authors produce the pattern. The expectation is to find that studies used a mix of methods, e.g. systematic literature review. 


\subsubsection{Search Process}

In this section the process followed in the SLR is described. These are the steps previous to the actual execution of the review. First, the keywords to be used in the queries were selected : " enterprise architecture" AND "Pattern")

The aim of this query is to produce a sample of the literature, in order to then answer the RQs. This query was executed with the scope of the full body of articles instead of the more popular Title-AbstractKeywords, in order to widen the variety of articles in the resulting sample. With these keywords at hand the databases to apply them to were selected:

- Scopus.

- ACM Digital Library.

- IEEE Xplore.

- Science Direct - Elsevier.

- Springer Link.

- Taylor and Francis.

- Web of science.

Using the Google Scholar database in the design was decided against, due to it containing results that are already present in all the databases above (Rouhani et al., 2015). However, due to the simplicity by which one is able to find specific articles, information about the references of articles and the articles that cite them, Google Scholar was used for the forward and backward citation gathering.

In accordance with the methodology selected (Rouhani et al., 2015), inclusion criteria is designed to produce a sample of studies that would best serve the goal of this study. In order to ensure recent scientific research as well as relevant patterns to today's challenges, articles published in the past 10 years were selected. To ensure scientific rigor studies published in journals and conference proceedings were selected, furthermore indexed books were also included because after an exploratory phase it was found that there were several books published containing repositories of patterns. For an international scope the search was limited to studies written in English. Finally, only articles referring to patterns were selected, in order to be able to answer the RQs. Inclusion Criteria:

- Peer-reviewed papers published in journals, conference proceedings, book chapters and books

- Published in the last decade

- Written in English

- Studies that focus on Patterns
In terms of the exclusion criteria to ensure scientific rigor short works, and non-studies (e.g. introductory texts) were excluded. In order to automate the gathering of bibliographic information articles without a DOI registry were excluded. Finally, to simplify the answering of the RQ, studies focusing on antipatterns and patterns referring to Software were excluded. The first due to the goal of compiling reusable solutions to common problems organizations face instead of things they should not do; the latter due to their narrow scope of how to program better software. Exclusion criteria:

- Short works, e.g. posters

- Duplicated work, unifying under the database with more results

- non-studies, e.g. Introduction texts to conference proceedings

- Articles without a DOI registry

- Articles referring to anti-patterns

- Articles referring to Software Architecture, or Software Patterns

Once the results were extracted from all the databases, the steps below were followed:

1. Eliminate all duplicates.

2. Based on the title whether exclusion criteria apply.

3. Based on the title and abstract select those articles where both inclusion criteria apply, and exclusion criteria don't apply.

4. Repeat step 3 but reading through the full text.

5. For each remaining article review the reference section and repeat steps 1 to 4, relaxing the "Articles without a DOI" criterion.

6. For each remaining article use Google Scholar to review the forward citations and repeat steps 1 to 4.

\subsection{Execution Phase}

In this phase the process and results of the execution phase of this SLR is explained. As defined during the design phase, the steps were followed and criteria defined was applied. First, a description of our experience executing the defined steps is given. Second, the form used to extract the useful information of the studies is shown.

\subsubsection{Query - Enterprise Architecture Patterns}

As shown in Table 1, the initial results of the query included 7669 non-unique items. After removing duplicates and those without DOI registry the sample 
Table 1: Results of Query.

\begin{tabular}{|l|l|}
\hline Database & $\begin{array}{l}\# \text { of } \\
\text { results }\end{array}$ \\
\hline Scopus & 2071 \\
\hline $\begin{array}{l}\text { The ACM Guide to Computing Litera- } \\
\text { ture }\end{array}$ & 81 \\
\hline IEEE Xplore & 1174 \\
\hline Science Direct & 609 \\
\hline Springer Link & 2746 \\
\hline Taylor and Francis & 125 \\
\hline Web of Science & 42 \\
\hline TOTAL & 7669 \\
\hline
\end{tabular}

size was reduced to 3236 articles. Those studies were then filtered by reading their titles and based on the exclusion criteria, resulting in 556 studies. Then the abstracts were read and those studies that referred to patterns were selected, this reduced the sample size to 33 articles. These were further refined to 16 studies based on their full text. From these 16 studies both forward and backward citations were gathered, which were then filtered based on their contents and more relaxed criteria. Thanks to the relaxed criteria it was possible to include reports and websites. The result was the final sample of 24 studies, as seen in Appendix A.

\subsubsection{Data Extraction}

In this section the data extraction form, that facilitates the gathering of the information present in the selected studies, is introduced. In 2 the information gathered from each study is shown. This information serves as the basis upon which answers to the RQs are drawn. Separately, for each pattern presented in the studies the information shown in Table 3 was gathered.

\subsubsection{Synthesis}

The final sample of studies contained 24 items, of which 11 are journal articles, 8 are conference papers and 2 are books, as shown in Table 4. While in Table 5 each study, their year of publication, what type study they were, as well as their number of citations is shown. The highest cited works were the 2011 book Architecture and Patterns for IT Service Management, Resource Planning, and Governance: Making Shoes for the Cobbler's Children with 82, and 2009's conference paper Using enterprise architecture management patterns to complement TOGAF with 76. A special note must be made regarding the 2019 journal article A Review and Typology of Circular Economy Business Model Patterns that within a short period of time has gathered 48 citations (P2). Although the number of citations has many contingencies it can be used to draw some comparisons. E.g. when comparing two articles of the same type the one with higher citations has informed a wider opinion than the article with a lower citation count.

Seven articles in the sample have been cited by less than 10 times, five of them conference proceedings and two journal articles, and three of them published in the last year. On the other hand, the other 17 studies in the sample have been cited between 10 and 82 times. In the sample the years 2009, 2011 and 2015 are the publication years for the biggest concentration of studies.

\section{RESULTS}

After the selection of the final sample and the subsequent extraction of the data the contents of the studies are explored. This section presents the findings and discussion of this review, as well as a narration of the challenges faced, and exploration done throughout the process.

In order to better present the results they will be aggregated based on the fields found in the sample. The fields found in the sample were: EA, BMI, BPM and ITSM. Each field will be explored deeper in the following subsections. There are two exceptions to this classification, studies P16 and P18. The first focuses on digital recruitment patterns for organizations, the latter focuses on change management for SMEs. This exclusion is based on their different fields, and low number (4) of patterns exposed, although they are present in the sample and resulting Pattern database (Appendix A and Appendix B)

\subsection{Enterprise Architecture}

In the EA field the focus on patterns has been split between patterns of enterprises, and patterns of the EA practice itself. The latter has been spearheaded by a group of researchers in the TUM who have been working on such patterns and concluded their work with the version 2 of their pattern catalog in 2015, codified as P10 in this work. This team of researchers are also responsible for P9, P15, P19 and P23, which represents $20 \%$ of our sample.

In Table 6 each study of the EA field found in the sample is shown. As mentioned before, P9, P10, P15, P19 and P23 focus on the management of EA as a practice. These Enterprise Architecture Management (EAM) patterns total 34 out of the 111 patterns. All other works focus on the Enterprise as a whole. The 
Table 2: Data Extraction Form - Article.

\begin{tabular}{|c|c|c|}
\hline No. & Extracted Data & Description \\
\hline 1 & $\begin{array}{l}\text { Bibliographic Information } \\
\text { of the study }\end{array}$ & $\begin{array}{l}\text { Information on the Authors, year of publication, medium of publication } \\
\text { and any publication ID (DOI, ISSBN, etc) }\end{array}$ \\
\hline 2 & Times cited & $\begin{array}{l}\text { As mentioned above, Google Scholar was used to gather how many } \\
\text { times each study was cited }\end{array}$ \\
\hline 3 & Type of document & $\begin{array}{l}\text { Journal, Conference proceedings, published book, Lecture Notes, dis- } \\
\text { sertation }\end{array}$ \\
\hline 4 & Research Method & No method, case study, survey, interviews, experiment, literature review \\
\hline 5 & Scope of patterns presented & $\begin{array}{l}\text { The patterns can be of a segment of the architecture, e.g. Business } \\
\text { layer, Strategy layer, etc. It could also be cross-layer but in the scope of } \\
\text { a function, e.g. HR. }\end{array}$ \\
\hline 6 & $\begin{array}{l}\text { Field of origin for the pat- } \\
\text { tern presented }\end{array}$ & $\begin{array}{l}\text { Where the pattern comes from, i.e. the field of research that prompted } \\
\text { the pattern }\end{array}$ \\
\hline 7 & Language of representation & $\begin{array}{l}\text { A formal modelling language (e.g. Archimate), representation for- } \\
\text { malisms (i.e. a Framework), a non-standard modelling language (boxes } \\
\text { and lines), written description }\end{array}$ \\
\hline 8 & $\begin{array}{l}\text { Number of Patterns pre- } \\
\text { sented }\end{array}$ & How many patterns are presented in the article \\
\hline 9 & Validation of the patterns & No validation, conceptual validation, expert panel, etc. \\
\hline
\end{tabular}

Table 3: Data Extraction Form - Pattern.

\begin{tabular}{|l|l|l|}
\hline No. & $\begin{array}{l}\text { Extracted } \\
\text { Data }\end{array}$ & Description \\
\hline 1 & Id & An identifier \\
\hline 2 & Name & $\begin{array}{l}\text { Name of the pattern as written } \\
\text { in the article }\end{array}$ \\
\hline 3 & Description & $\begin{array}{l}\text { Description, or summary of } \\
\text { the pattern as written in the ar- } \\
\text { ticle }\end{array}$ \\
\hline 4 & Source & $\begin{array}{l}\text { Which article it appeared on, } \\
\text { could be possible that multi- } \\
\text { ple articles refer to the same } \\
\text { pattern by name }\end{array}$ \\
\hline 5 & $\begin{array}{l}\text { Publication } \\
\text { year }\end{array}$ & $\begin{array}{l}\text { What year was the pattern } \\
\text { published on }\end{array}$ \\
\hline 6 & $\begin{array}{l}\text { Field of } \\
\text { origin }\end{array}$ & $\begin{array}{l}\text { From which field does the pat- } \\
\text { tern come from }\end{array}$ \\
\hline 7 & $\begin{array}{l}\text { The patterns can be of a seg- } \\
\text { ment of the architecture, e.g. } \\
\text { Business layer, Strategy layer, } \\
\text { etc. It could also be cross- } \\
\text { layer but in the scope of a } \\
\text { function, e.g. HR. }\end{array}$ \\
\hline
\end{tabular}

publication year was also shown, where it can be seen that most of the works in the sample are from 2009 (44\%), barely inside the scope of the SLR. Among these studies the one with most citations is P12 where 32 patterns are defined, dealing with every degree of application support on Business Processes. E.g. a business process is entirely supported by an application, or a business process having no application sup-
Table 4: Studies by Type.

\begin{tabular}{|l|l|}
\hline Study type & Number of study \\
\hline book & 2 \\
\hline Book Section & 1 \\
\hline Conference Paper & 8 \\
\hline Journal Article & 11 \\
\hline Report & 1 \\
\hline Website & 1 \\
\hline Total general & $\mathbf{2 4}$ \\
\hline
\end{tabular}

porting it.

These studies base most of their patterns on their own experiences as experts in the field, which is classified as No Method. Except for P13 which performed a literature review in order to gather the patterns they presented.

Finally, in terms of means of representation all the works focusing on EAM have followed the same format. Which is understandable, as they're outcomes of the same research group. Other studies use Archimate and a written description (P4, P12). Where the written description contains a summary of the solution, an example of it, with $\mathrm{P} 4$ also explaining the problem the pattern solves. P13 uses only a written description and P14 uses multiple diagramming languages (UML, BPMN, Archimate) as well as written description of the context, problem and solution. 
Table 5: Studies by Year of Publication and Citations.

\begin{tabular}{|l|l|l|l|l|l|l|l|}
\hline ID & Study Type & $\begin{array}{l}\text { Publication } \\
\text { Year }\end{array}$ & $\begin{array}{l}\text { Number } \\
\text { of cita- } \\
\text { tions }\end{array}$ & ID & Study Type & $\begin{array}{l}\text { Publication } \\
\text { Year }\end{array}$ & $\begin{array}{l}\text { Number } \\
\text { of } \\
\text { cita- } \\
\text { tions }\end{array}$ \\
\hline P1 & Journal Article & 2018 & 3 & P13 & Journal Article & 2009 & 17 \\
\hline P2 & Journal Article & 2019 & 48 & P14 & Book & 2014 & 29 \\
\hline P3 & Conference Paper & 2010 & 11 & P15 & Conference Paper & 2015 & 5 \\
\hline P4 & Book Section & 2019 & 0 & P16 & Conference Paper & 2015 & 2 \\
\hline P5 & Book & 2011 & 82 & P17 & Conference Paper & 2010 & 0 \\
\hline P6 & Journal Article & 2015 & 51 & $\mathbf{P 1 8}$ & Conference Paper & 2011 & 1 \\
\hline P7 & Journal Article & 2019 & 0 & $\mathbf{P 1 9}$ & Journal Article & 2009 & 42 \\
\hline P8 & Conference Paper & 2016 & 13 & $\mathbf{P 2 0}$ & Journal Article & 2017 & 59 \\
\hline P9 & Journal Article & 2009 & 14 & $\mathbf{P 2 1}$ & Journal Article & 2018 & 28 \\
\hline P10 & Report & 2015 & 0 & $\mathbf{P 2 2}$ & Conference Paper & 2013 & 30 \\
\hline P11 & Journal Article & 2011 & 43 & P23 & Conference Paper & 2009 & 76 \\
\hline P12 & Journal Article & 2011 & 52 & $\mathbf{P 2 4}$ & Website & 2011 & 47 \\
\hline
\end{tabular}

Table 6: EA Studies and Patterns.

\begin{tabular}{|c|c|c|c|c|}
\hline ID & $\begin{array}{l}\text { Research } \\
\text { Method }\end{array}$ & $\begin{array}{c}\text { Publication } \\
\text { Year }\end{array}$ & $\overline{\text { Patterns }}$ & $\begin{array}{c}\text { Citation } \\
\text { Count }\end{array}$ \\
\hline P4 & $\begin{array}{c}\text { No } \\
\text { Method }\end{array}$ & 2019 & 4 & 0 \\
\hline P9 & $\begin{array}{c}\text { No } \\
\text { Method }\end{array}$ & 2009 & 3 & 14 \\
\hline P10 & $\begin{array}{c}\text { No } \\
\text { Method }\end{array}$ & 2015 & 23 & 0 \\
\hline P12 & $\begin{array}{c}\text { No } \\
\text { Method }\end{array}$ & 2011 & 32 & 52 \\
\hline$\overline{\text { P13 }}$ & $\begin{array}{l}\text { Literature } \\
\text { review }\end{array}$ & 2009 & 28 & 17 \\
\hline P14 & No & 2014 & 13 & 29 \\
\hline$\overline{P 15}$ & $\begin{array}{c}\text { No } \\
\text { Method }\end{array}$ & 2015 & 2 & 5 \\
\hline P19 & $\begin{array}{c}\text { No } \\
\text { Method }\end{array}$ & 2009 & 6 & 42 \\
\hline $\mathbf{P 2 3}$ & $\begin{array}{c}\text { No } \\
\text { Method }\end{array}$ & 2009 & 0 & 76 \\
\hline Total & & & 111 & 235 \\
\hline
\end{tabular}

\subsection{Business Model Innovation}

The patterns found coming from the BMI field focus on describing the Business Model, where frameworks like the Business Model Canvas and its' constructs are popular in our sample (Osterwalder and Pigneur, 2010). These constructs include revenue stream and customers. Another interesting finding is the research on Business Models from the Sustainable Business Development field, which focus on evaluating what types Business Models are sustainable (P2, P7, P21). For example, $\mathrm{P} 2$ focuses in the sub-field of Circular Economy Business Development.

As can be seen in Table 7 the primary pattern publication is P20 in 2017, that gathered multiple repos-
Table 7: Business Model Studies and Patterns.

\begin{tabular}{|c|c|c|c|c|}
\hline ID & $\begin{array}{l}\text { Research } \\
\text { Method }\end{array}$ & $\begin{array}{c}\text { Publication } \\
\text { Year }\end{array}$ & Patterns & $\begin{array}{l}\text { Citation } \\
\text { count }\end{array}$ \\
\hline P1 & $\begin{array}{l}\text { Systematic } \\
\text { literature } \\
\text { review }\end{array}$ & 2018 & 30 & 3 \\
\hline P2 & $\begin{array}{c}\text { Literature } \\
\text { review }\end{array}$ & 2019 & 6 & 48 \\
\hline P6 & $\begin{array}{c}\text { Market } \\
\text { research }\end{array}$ & 2015 & 27 & 51 \\
\hline P7 & $\begin{array}{l}\text { Case } \\
\text { studies }\end{array}$ & 2019 & 7 & 0 \\
\hline P8 & $\begin{array}{l}\text { Market } \\
\text { research }\end{array}$ & 2016 & 27 & 13 \\
\hline$\overline{\mathbf{P 2 0}}$ & $\begin{array}{c}\text { Literature } \\
\text { review }\end{array}$ & 2017 & 176 & 59 \\
\hline P21 & $\begin{array}{c}\text { Literature } \\
\text { review }\end{array}$ & 2018 & 45 & 28 \\
\hline Total & & & 318 & 202 \\
\hline
\end{tabular}

itories in the field from previous work and consolidated it. P20 has more than 176 Business Model Patterns, which prompted others to follow and expand on, further extending the number of patterns. It has also served the sustainable business development field as a basis for their own work, both for them to expand the repository (P2) as well as evaluate the patterns through sustainability research (P21).

In Table 7 it can be seen that all publications happened in the past four years. With the ones focusing on sustainability being even more recent.

For research methods, these studies leveraged the existing literature, in the form of reviews, as a source for the patterns presented (57\%). Those that deviated from the literature went instead to the market and analyzed how real-world organizations operate.

Finally, the means of representation they used was heterogeneous. P1 uses the Business Model Canvas as 
presented by Osterwalder and Pigneur (Osterwalder and Pigneur, 2010). P2 develops a morphology based on the Business Model Canvas. P6 uses a framework developed by Köster (2013) which mainly presents the constructs defined by the Business Model Canvas in four categories: Supply model, Customer model, Value creation model, and financial model. P7 uses only written descriptions of the solutions. P8 uses the template defined by Weil et al. (Weill et al., 2005) where each pattern has a name, a short description and a real-world organization that uses it. P20 compiles a table with pattern name, description, alternative names, example of the real-world and its' source study. P21 used a template based on the one presented by Alexander et al. (1977) with written descriptions of the problem and the repeatable solution. Except for P7 that uses only written descriptions and P21 that uses a proper pattern representation, all articles from this field can be split by similarity into two groups: the ones that use the constructs from the Business Model Canvas or similar (P1, P2, P6), the ones that compiled a table with minimal information (P8, P20).

\subsection{Business Process Management}

The BPM field had their own primary publication in 2011 with P24 where the authors have been working through multiple articles and publishing their work in web format. Their work is publicly accessible through their website which makes it easy for other researchers to use it for future work, something that shows in their citation count. They aim to be exhaustive in their work, and it shows, as their repository now contains 127 patterns for Business Process Modeling. However, no recent articles were found other than the publication of a book gathering their findings in 2016 (Russell et al., 2016). They use a colored petri net to represent their patterns in diagrams, along with a written description of the solution. As a source for their patterns they leverage their own expertise.

The other work from this field in our sample was P11 in 2011, using an abstract representation of an enterprise based on the most essential processes. They use written descriptions and diagrams written in ANSI/IEEE 1471-2000. They have based their patterns on their own experience and have seen them applied to many organizations in Chile.

\subsection{IT Service Management}

The articles from the ITSM field that were in the final sample were clearly split on either conference papers or a book, where the book (P5) has the highest citation count out of the entire sample. The conference papers (P3, P17 and P22) only documented 10 patterns among them, however they hinted at a technical report by the same authors that was not possible to acquire. It must be mentioned that the authors were unable to access P5 in its' current 2nd edition, instead only the 1st edition from 2007 was analysed.

Table 8: ITSM Studies and Patterns.

\begin{tabular}{|c|c|c|c|c|}
\hline ID & $\begin{array}{c}\text { Research } \\
\text { Method }\end{array}$ & $\begin{array}{c}\text { Publication } \\
\text { Year }\end{array}$ & Patterns & $\begin{array}{c}\text { Citation } \\
\text { count }\end{array}$ \\
\hline P3 & $\begin{array}{c}\text { No } \\
\text { Method }\end{array}$ & 2010 & 6 & 11 \\
\hline P5 & $\begin{array}{c}\text { No } \\
\text { Method }\end{array}$ & 2011 & 19 & 82 \\
\hline P17 & $\begin{array}{c}\text { No } \\
\text { Method }\end{array}$ & 2010 & 1 & 0 \\
\hline P22 & $\begin{array}{c}\text { No } \\
\text { Method }\end{array}$ & 2013 & 3 & 30 \\
\hline Total & & & 29 & 123 \\
\hline
\end{tabular}

As for means of representation, As can be seen in Table 8 all of the studies in this field base their patterns on experience. With the special mention of $\mathrm{P} 22$ which translates the ITIL standard into Archimate concepts. P17 and P3 use a template that is based on Alexander et al. (1977) and describes a context, a problem, the forces that foster the use of a pattern, the solution itself, its' consequences and some facts to help the understanding and usage of the solution, for example depending on the number of systems managed in a remote location the use of a single distributor may not be enough. The patterns are accompanied by diagrams made using a non-standard modelling language and UML. Both works refer to a research group that has published a technical report with a more complete collection of patterns, but the report was inaccessible to the authors of this paper. Finally, P5 uses written descriptions without following a specific template like other studies in the sample, as well as with UML and non-standard diagrams.

\section{DISCUSSION}

In this section, the results of the SLR and overall findings are shown. This section also contains the discussion on the Research Questions. Finally, its' limitations and possible future work are discussed.

\subsection{General Discussion}

During the overall execution of the SLR it was noticed that the concept of patterns has been used by all fields in the sample with different time spans. In Figure 2 it can be seen how each of the fields has peaks 


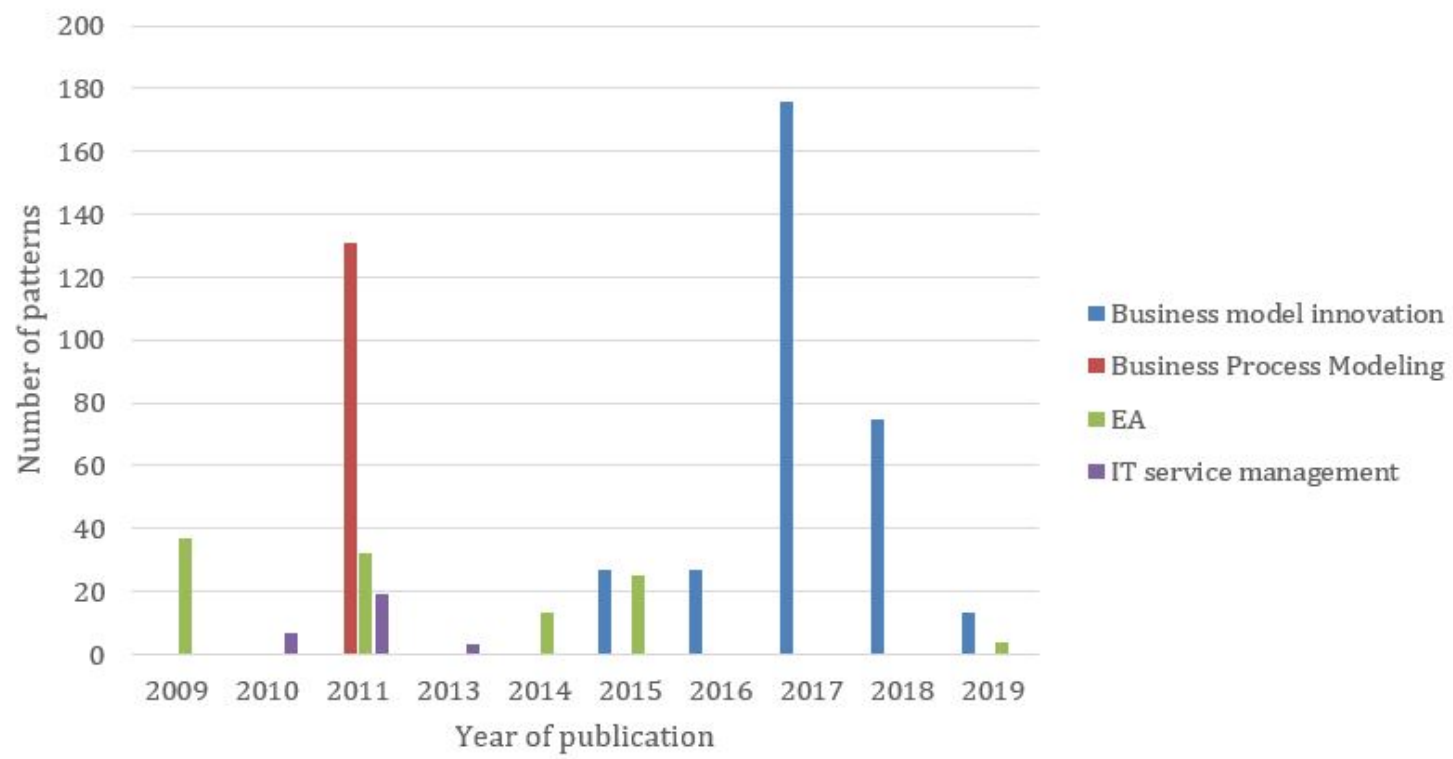

Figure 2: Patterns per Year and Field.

in different years. The latest one being the studies on BMI, particularly in the Sustainable Business Development field. The recent surge of the BMI field's effort on documenting the patterns has been welcomed with open arms by the academic community, as seen by the citation count mentioned in earlier sections. Such interest extends to the sub-field of Sustainable Business Models, that expands the Business Model Patterns. P2 which expands upon the Repository and adds more Business Model Patterns. Contrary to all other studies in this sample, all the studies related to BMI, SBM and Circular Economy are based around the framework proposed by Osterwalder and Pigneur (Osterwalder and Pigneur, 2010). Although the representation of the patterns may differ, their basic constructs are the same, which would make it possible to translate these patterns into an EA representation of them, based on the work of Iacob et al. (2014). This method would pave the way to take these Business Model Patterns repositories into EA Patterns. Being able to relate the patterns extracted from Sustainable Business Models and translating them to EA is aligned with the overall interest of society to a more sustainable world. With the call for sustainability, as seen by the Sustainable Development Goals of the UN (United Nations, 2015), it means that organizations will need to develop new functions or transform their current ones. This change could be supported by EA, and, being a generalized need, would benefit from having a repository of patterns to draw from.

\subsection{State of the Literature on Enterprise Architecture Patterns}

Each of the 24 studies reviewed in this SLR have described patterns, however not all of them seem to be written in a way that can be used by future works. For example in the conference proceedings and journal articles, where the authors report mostly on how they arrived at the patterns (P3, P17), or describes how one could extract and write patterns (P16, P22), but do very little in actually documenting them. As such, when extracting the information, which in Section 2.2.2 we defined as name and description, there are some patterns without a description as well as some where it was difficult even to gather the names of. This lack of information may be related to the space limitations when submitting studies for publication in conferences or journals. Which is aligned with our findings that the most detailed and complete patterns are found in books, technical reports and online databases.

With space being such a valuable resource in journal articles and conference papers it raises the question what is the best way to gather patterns in a way that is usable for future research as well as practitioners. Within this SLR, books and technical reports focused more on the patterns themselves, while journal articles and conference proceedings focused more on methods or presented sample patterns. Although P24 fused the two, by publishing each new kind of pattern in journal articles while at the same time keeping the online repository updated they were able to present a high amount of information on their work 
while avoiding the space limitations scientific publishing implies.

Based on the initial definition, patterns solve a repeating problem. In the case of EA patterns then, the problem is a deficit in the organization as perceived by the stakeholders. Thus, EA practitioners would be in the best position to detect both the problems that repeat themselves, as well as the solutions that could be reused to meet them. This line of thinking means that researchers must be in contact with practitioners far and wide in order to expand patterns, or that researchers must be practitioners as well. This poses a limitation, or it could be taken as an opportunity to include practitioners in future works on patterns.

\subsection{Fields Researching Patterns}

On Figure 3 we have classified the four main types of patterns found through the SLR in terms of the four main layers of the Archimate Language (Lankhorst, 2017). Based on Iacob et al. (2014) and the Archimate constructs they use to describe a Business Model (Osterwalder and Pigneur, 2010) it can be concluded that Business Model Patterns are confined to the Strategy and Business layers. While the Business Process Patterns was mapped to the Business Layer due to its' scope, Business Processes, which is enclosed in this layer.

\begin{tabular}{|l|c|c|c|}
\hline Strategy & $\begin{array}{c}\text { Business } \\
\text { Model } \\
\text { Patterns }\end{array}$ & $\begin{array}{c}\text { Business Process } \\
\text { Patterns }\end{array}$ & \\
\hline Business & $\begin{array}{c}\text { IT Service } \\
\text { Management } \\
\text { Patterns }\end{array}$ & $\begin{array}{c}\text { Enterprise } \\
\text { Architecture } \\
\text { Patterns }\end{array}$ \\
\hline Application & \\
\hline Technology & \\
\hline
\end{tabular}

Figure 3: Classification of Fields.

EAM Patterns are omitted from this graph. This is due to their focus on the practice of EA itself, the methods enterprise architects use to gather information, as well as how they present it to stakeholders. As such these patterns are more akin to an EA framework and methodology. Thus, although the focus of the EAM patterns is the EA practice itself, this is different to the EA patterns, which is the enterprise.

\subsection{Means of Representation}

The overall heterogeneous way to represent patterns is natural due to the multitude of fields and languages comes into play. However just as Perroud and Inversini presented in their work (P14), these patterns may need to express concepts that any one modelling language is unable to combine. They (P14) used multiple languages, each showing a specific point of view to the pattern, and tied it all with natural language description, due to the complexity of communicating these patterns. In detail, the structure proposed by Alexander et al. (1977) should have the following components:

- A title

- A diagram

- An Introduction describing the context and how it builds larger patterns;

- A detailed description of the problem, its' validity, and ways the pattern manifests to solve it

- A detailed description of the solution, written as instructions for people to follow;

- A diagram of the solution;

- How it links to other patterns, both smaller and larger in scope.

Such a structure is used in a similar fashion by some of the works in the sample, (P14, P3, P17), while all of the works described at least some of the concepts. It is the authors' belief that the structure detailed by Alexander et al. (1977), is the best basis to represent EA patterns. Such a statement is echoed by a study by Kotzé et al. (2012) in the EA field that has laid out guidelines to the elaboration and documentation of patterns, as well as defined a pattern template, which follows:

- Pattern Name: A unique name to identify a pattern.

- Problem: The design problem which is addressed the creation of a pattern.

- Context: In which circumstances and domain is this pattern applicable?

- Forces: The various forces that impact the creation or existence of a pattern.

- Solution: Describe what needs to be done as a solution that resolves forces from strongest in this context in relation to addressing the recurring problem.

- Related Patterns: What enterprise architecture patterns are closely related to this one?

- Rationale: Is a description of why the solution is an appropriate one and not another.

- Example: An artefact (e.g. a graphical model, an algorithm, a formula, a structured rule (text), etc.), which illustrates how the pattern operates.

Such a template comes from a study on how to write patterns, but does not elaborate any examples. Thus 
Kotzé et al. (2012) did not run into some of the issues that authors in our sample did. As evidenced by the template used by P14, shown in Figure 4, the solution section of the template requires a longer and deeper understanding. This is due to the multiple viewpoints and layers a pattern may cross, like Pattern170, that describes business, application and technology layers.

\begin{tabular}{ll} 
Table 2.10 Structure of a pattern & \\
\hline Section & Subsections \\
\hline X.11.1 Introduction & Name and overview \\
& Definition \\
X.11.2 Example & \\
X.11.3 Context & \\
X.11.4 Problem & \\
X.11.5 Solution & Vision \\
& Principles \\
& Holistic view \\
& Business view \\
& Data and application view \\
& Technology view \\
X.11.6 Resulting context & Interaction \\
& Consequences \\
X.11.7 References & \\
\hline
\end{tabular}

Figure 4: Table 2.10, Taken from P14.

Both P14 and Kotzé et al. (2012) detail a representation of EA patterns that overlap on many of the concepts they propose, with some exceptions. In Figure 4 there are some concepts that are missing according to Kotzé et al. (2012) representation but can be found in the details: Forces and Related patterns. This means that P14 has every concept proposed by Kotzé et al. (2012) except for the rationale behind the proposed solution. Also, when one compares this way of representation with the one proposed by Alexander et al. (1977) it's missing a description of the validity of the problem. Due to this, we propose that the template presented by $\mathrm{P} 14$ can be enhanced upon with a more exhaustive structure where all the pieces can be perceived at first glance, and the rationale behind both the problem and the solution is explicit.

\subsection{Methodologies for Pattern Extraction}

A Challenge faced by all the fields in this SLR was the gathering of the patterns. While the Business Model Patterns can be extracted from an organization through literature reviews and researching real world organizations. On the other hand the patterns presented by the EA field are based on authors' experience. For example P14 mentioning that the source of these patterns is the day to day experience of the practitioner and detecting a repeating problem. This mention of repeating problem is also present in other works on patterns (Alexander et al., 1977). Another avenue seen is presenting a framework that is built with discreet choices of concepts and then building patterns exhausting all possible combinations. This method is used by P2, P11, P12, and in a more limited way P24 which strives for a exhaustive work but do not explicitly show all possible combinations. Finally, P22 took current standards and made them into patterns.

As seen in Section 3, the $50 \%$ of studies in the sample based the patterns from the author's experience. When reviewing the definitions by Alexander (Alexander et al., 1977) the source of patterns is an experienced professional experiencing the same problem again and again, so this would explain this method's commonality. What is missing, however, is the argumentation on the existence of the problem, one that fosters the need for a pattern in the first place. With most of the studies in the sample were missing a framing of the problem they're set to solve.

The second most common method of extracting patterns is the literature review (25\%), which extracts patterns from current literature. Determining what method is used in the sources of these literature reviews is outside the scope of this SLR. These sources apply their own methods.

The studies that deviate from literature review and author's experience are P5 and P17 which base their patterns on standard practices. In case of P5 it's the ITIL library, which dictates practices on how to operate the IT function of an enterprise. With P17 it's a framework of their own which extends upon ITIL, Cobit, CMMI and other standards, that models the entire IT function as an enterprise by its' own worth. This approach could be expanded upon to include other standards that detail how organizations should act.

In order to give the patterns validity, their definition must come accompanied by some kind of argument supporting that using the pattern indeed solves the problem (Alexander et al., 1977). In the sample this came from identifying organizations that worked under patterns in question (P20, P1, P9, P11, $\mathrm{P} 14, \mathrm{P} 16, \mathrm{P} 21)$, from personally applying the patterns (P18), from having practitioners apply the pattern (P8), from building business cases (P5), or from having other researchers validate the patterns found (P1, P24). However, the majority of the works in the sample describe no manner of validation (P2, P3, P4, P6, P7, P8, P10, P12, P13, P15, P17, P19, P22, P23), a majority of the sample. 


\section{CONCLUSIONS}

The goal of this SLR was to investigate the different patterns, if any, that exist in the field of EA. Collecting all the patterns found in one resource, as well as identify other possible source of patterns. Through this process other fields related to EA were identified. These have also boarded the subject, producing studies that can be built upon from the EA field, as proposed in the discussion section. These fields are BMI, Sustainable Business Development, BPM and ITSM.

It was found that among them there are 593 patterns throughout the sample selected, although some of these were written with very shallow details, others were written as exhaustively as possible. This heterogeneity on scope, depth, and means of representation means that future studies could consolidate these patterns into a comparable form.

This SLR has some limitations, its' most limiting factor is its' focus, the concept of pattern. Other fields related to EA could be researching concepts similar to patterns but with different names. For example, the work on Human Resource Architecture might be taken as EA patterns, specifically for the HR function (Lepak and Snell, 2002).

Following this reasoning, the search for patterns in other fields that could be of use to EA could be expanded. First, by identifying what other research fields exist that are neighboring EA that could serve as reference disciplines and where can they be found. Said fields could then be used to expand the pattern repository.

A second limitation is the scope of this SLR, as it excludes grey literature not present in the databases queried. Through the author's personal experience, in the IT architecture field there are patterns that would be a good fit in this study. Such as Patterns of Enterprise Application Architecture (Fowler, 2012) that details dozens of application patterns as well as deployment patterns. Furthermore, subjects like cloud architectures, of which multiple books are available, are missing from the sample and would be valuable to a final repository (Wilder, 2012; Erl et al., 2013; Kavis, 2014; Erl et al., 2015).

Lastly, future research can work towards translating the patterns found here into a complete pattern template and written in languages useful for EA practitioners, e.g. Archimate. Thus, Compiling a set of ready-to-use solutions to repeating problems in realworld organizations. Such a set would need to classify both problems, solutions and their consequences. Imagine an architect looking for ways to improve sustainability of an enterprise, they could peruse such a classified set of patterns and select a solution that suits their case.

The EA field can benefit greatly from the identification, documentation and publication of patterns in a way that is accessible for practitioners and researchers alike. Such an effort could be accelerated with the help of the practitioner community, who run into the recurring problems that give birth to patterns (Alexander et al., 1977). If built, such a repository would serve EA efforts, which in this time of great change will be of great value to organizations.

In order to support the looming massive changes to organizations, the challenges they will face, although big individually, will be repeatable problems. Consequently, they could be faced using patterns. Having a set of patterns, architects would be able to meet these challenges with higher success.

\section{REFERENCES}

Alexander, C., Ishikawa, S., and Silverstein, M. (1977). A pattern language: towns, buildings, construction. Oxford University Press, New York, NY, USA.

Erl, T., Cope, R., and Naserpour, A. (2015). Cloud Computing Design Patterns (paperback). The Prentice Hall Service Technology Series from Thomas Erl. Pearson Education.

Erl, T., Puttini, R., and Mahmood, Z. (2013). Cloud Computing: Concepts, Technology \& Architecture. The Prentice Hall service technology series from Thomas Erl. Prentice Hall.

Fowler, M. (2012). Patterns of Enterprise Application Architecture. Addison-Wesley Professional.

Gamma, E. and al, E. (1995). Design Patterns - Elements of Object Oriented Software Architecture.

Iacob, M. E., Meertens, L. O., Jonkers, H., Quartel, D. A., Nieuwenhuis, L. J., and van Sinderen, M. J. (2014). From enterprise architecture to business models and back. Software and Systems Modeling, 13(3):1059_ 1083.

Kavis, M. J. (2014). Architecting the Cloud: Design Decisions for Cloud Computing Service Models (SaaS, PaaS, and IaaS). Wiley CIO. Wiley.

Kitchenham, B. and Charters, S. (2007). Guidelines for performing Systematic Literature Reviews in Software Engineering. Technical Report 3.

Köster, O. (2013). Systematik zur Entwicklung von Geschäftsmodellen in der Produktentstehung. $\mathrm{PhD}$ thesis, University of Paderborn.

Kotzé, P., Tsogang, M., and van der Merwe, A. (2012). A Framework for Creating Pattern Languages for Enterprise Architecture. pages 1-20.

Lankhorst, M. (2017). Enterprise Architecture at Work. The Enterprise Engineering Series. Springer Berlin Heidelberg, Berlin, Heidelberg, 3rd edition.

Lankhorst, M. M., Proper, H. A., and Jonkers, H. (2009). The architecture of the ArchiMate language. In Lec- 
ture Notes in Business Information Processing, volume 29 LNBIP, pages 367-380. Springer Verlag.

Lepak, D. P. and Snell, S. A. (2002). Examining the Human Resource Architecture: The Relationships Among Human Capital, Employment, and Human Resource Configurations. Journal of Management, 28(4):517543.

Osterwalder, A. and Pigneur, Y. (2010). Business model generation: a handbook for visionaries, game changers, and challengers.

Rouhani, B. D., Mahrin, M. N., Nikpay, F., Ahmad, R. B., and Nikfard, P. (2015). A systematic literature review on Enterprise Architecture Implementation Methodologies. Information and Software Technology, 62:120.

Russell, N., van der Aalst, W., and ter Hofstede, A. (2016). Workflow Patterns: The Definitive Guide. MIT Press.

The Open Group (2018). The TOGAF® Standard, Version 9.2.

United Nations (2015). Transforming Our World: The 2030 Agenda for Sustainable Development. Technical report, United Nations Publishing, New York, New York, USA.

Weill, P., Malone, T. W., D'urso, V. T., Herman, G., and Woerner, S. (2005). Do Some Business Models Perform Better than Others? A Study of the 1000 Largest US Firms. Technical report.

Wilder, B. (2012). Cloud Architecture Patterns: Using Microsoft Azure. "O'Reilly Media, Inc.".

Wolfswinkel, J. F., Furtmueller, E., and Wilderom, C. P. M. (2013). Using grounded theory as a method for rigorously reviewing literature. European Journal of Information Systems, 22(1):45-55.

Zachman, J. A. (1987). A framework for information systems architecture. IBM systems journal, 26(3):276292.

\section{APPENDIX A: SAMPLE}

- P1: Weking, J., Hein, A., Böhm, M., \& Krcmar, H. (2018). A hierarchical taxonomy of business model patterns. Electronic Markets, 9(1), 97-104. https://doi.org/10.1007/s12525-018-0322-5

- P2: Lüdeke-Freund, F., Gold, S., \& Bocken, N. M. P. (2019). A Review and Typology of Circular Economy Business Model Patterns. Journal of Industrial Ecology, 23(1), 36-61. https://doi.org/10.1111/jiec.12763

- P3: Da Silva, L. F., \& E Abreu, F. B. (2010). An IT Infrastructure patterns approach to improve IT service management quality. Proceedings - 7th International Conference on the Quality of Information and Communications Technology, QUATIC 2010, 171-176. https://doi.org/10.1109/QUATIC.2010.34
- P4: Yamamoto, S., \& Zhi, Q. (2019). ArchiMate Business Model Patterns to e-Healthcare. In Y.-W. Chen, A. Zimmermann, R. J. Howlett, \& L. C. Jain (Eds.), Smart Innovation, Systems and Technologies (Vol. 145, pp. 11-20). https://doi.org/10.1007/978-981-13-8566-7_2

- P5: Betz, C. T. (2011). Architecture and Patterns for IT Service Management, Resource Planning, and Governance: Making Shoes for the Cobbler's Children. In Architecture and Patterns for IT Service Management, Resource Planning, and Governance: Making Shoes for the Cobbler's Children. https://doi.org/10.1016/C2010-0-65839-1

- P6: Amshoff, B., Dülme, C., Echterfeld, J., \& Gausemeier, J. (2015). Business model patterns for disruptive technologies. International Journal of Innovation Management, 19(3), 1540002. https://doi.org/10.1142/S1363919615400022

- P7: Zufall, J., Norris, S., Schaltegger, S., Revellio, F., \& Hansen, E. G. (2019). Business model patterns of sustainability pioneers - Analyzing cases across the smartphone life cycle. Journal of Cleaner Production, 118651. https://doi.org/10.1016/j.jclepro.2019.118651

- P8: Remane, G., Hildebrandt, B., Hanelt, A., \& Kolbe, L. M. (2016). Discovering new digital business model types - A study of technology startups from the mobility sector. Pacific Asia Conference on Information Systems, PACIS 2016 Proceedings.

- P9: Buckl, S., Ernst, A., Kopper, H., Marliani, R., Matthes, F., Petschownik, P., \& Schweda, C. (2009). EA Management Patterns for Consolidations after Mergers. SE 2009 - Workshopband, Workshop on Patterns in Enterprise Architecture Management (PEAM 2009), 19, 67-78. https://doi.org/10.1016/j.cell.2008.01.015

- P10: Khosroshahi, P. A., Hauder, M., Schneider, A. W., \& Matthes, F. (2015). EAM Pattern Catalog Version 2.0. In Faculty for Informatics, TU München.

- P11: Barros, O., \& Julio, C. (2011). Enterprise and process architecture patterns. Business Process Management Journal, 17(4), 598-618. https://doi.org/10.1108/14637151111149447

- P12: Šaša, A., \& Krisper, M. (2011). Enterprise architecture patterns for business process support analysis. Journal of Systems and Software, 84(9), 1480-1506. https://doi.org/10.1016/j.jss.2011.02.043

- P13: Lankhorst, M. M., \& Luttighuis, P. H. W. M. O. (2009). Enterprise architecture patterns for 
multichannel management. Software Engineering (Workshops), 150(March), 31-42. Retrieved from https://dl.gi.de/handle/20.500.12116/20378

- P14: Perroud, T., \& Inversini, R. (2014). Enterprise architecture patterns: Practical solutions for recurring IT-architecture problems. In Enterprise Architecture Patterns: Practical Solutions for Recurring IT-Architecture Problems (Vol. 9783642375). https://doi.org/10.1007/9783-642-37561-3

- P15: Schneider, A. W., \& Matthes, F. (2015). Evolving the EAM pattern language. The 20th European Conference, 1-11. https://doi.org/10.1145/2855321.2855367

- P16: Alamro, S., Dogan, H., \& Phalp, K. (2015). Forming Enterprise Recruitment Pattern Based on Problem-Oriented Conceptual Model. Procedia Computer Science, 64, 298-305. https://doi.org/10.1016/j.procs.2015.08.493

- P17: da Silva, L. F., \& e Abreu, F. B. (2010). Patterns for IT Infrastructure Design. Proceedings of the 15th European Conference on Pattern Languages of Programs (EuroPLoP'2010), 1-8.

- P18: Makna, J., \& Kirikova, M. (2011). Patternsbased is change management in smes. In W. W. Song, S. Xu, C. Wan, Y. Zhong, W. Wojtkowski, G. Wojtkowski, \& H. Linger (Eds.), Information Systems Development: Asian Experiences (pp. 55-66). https://doi.org/10.1007/978-1-44197355-9_5

- P19: Moser, C., Junginger, S., Brückmann, M., \& Schöne, K.-M. (2009). Some Process Patterns for Enterprise Architecture Management. Software Engineering 2009 - Workshopband, 19-30.

- P20: Remane, G., Hanelt, A., Tesch, J. F., \& Kolbe, L. M. (2017). The Business Model Pattern Database-A Tool For Systematic Business Model Innovation. International Journal of Innovation Management, 21(1). https://doi.org/10.1142/S1363919617500049

- P21: Lüdeke-Freund, F., Carroux, S., Joyce, A., Massa, L., \& Breuer, H. (2018). The sustainable business model pattern taxonomy-45 patterns to support sustainability-oriented business model innovation. Sustainable Production and Consumption. https://doi.org/10.1016/j.spc.2018.06.004

- P22: Vicente, M., Gama, N., \& Silva, M. M. Da. (2013). Using archimate to represent ITIL metamodel. Proceedings 2013 IEEE International Conference on Business Informatics, IEEE CBI 2013, 270-275. https://doi.org/10.1109/CBI.2013.45
- P23: Buckl, S., Ernst, A. M., Matthes, F., Ramacher, R., \& Schweda, C. M. (2009). Using enterprise architecture management patterns to complement TOGAF. Proceedings - 13th IEEE International Enterprise Distributed Object Computing Conference, EDOC 2009, 34-41. https://doi.org/10.1109/EDOC.2009.30

- P24: van der Aalst, W. M. P., \& Hofstede, A. ter. (2011). Workflow patterns. Retrieved October 21, 2019, from http://www.workflowpatterns.com/

\section{APPENDIX B: PATTERNS}

Due to the size of the resulting patterns, they have been published under the following address: https://github.com/robertorgarcia/EAPatterns 